
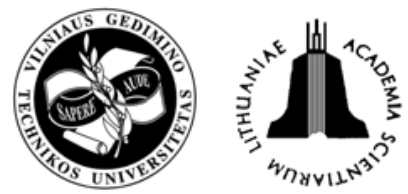

\title{
MODELLING AND INVESTIGATION OF CAR COLLISIONS
}

\author{
Arūnas Tautkus ${ }^{1}, \check{Z ̆ i l v i n a s ~ B a z a r a s ~}^{2}$ \\ Dept of Mechanical Technology, Panevezzys Institute, Kaunas University of Technology, \\ Klaipedos g. 1, LT-35209 Panevėžys, Lithuania \\ E-mails: ${ }^{1}$ arunas.tautkus@ktu.lt; ${ }^{2}$ zilvinas.bazaras@ktu.lt
}

Received 20 May 2007; accepted 10 September 2007

\begin{abstract}
While investigating collisions with immovable obstacles it is necessary to assess the place of contact, its character and the speed of vehicles before the contact. These parameters depend on the obstacle. The most common cases were analyzed in the article: collision with an immovable obstacle which deformed only a part of the fore of vehicle (collision with a tree, a bollard, etc.); collision with an immovable obstacle which deformed the whole fore of vehicle (collision with a wall, etc.).
\end{abstract}

Keywords: collision, immovable obstacle, safety.

\section{Introduction}

The success of car collision research is determined by the reliability of the initial data from the place of traffic accident. In the place of traffic accident the traces of braking distance and skidding are often found, though in some cases they are not seen very clearly or are too blind. However, the traces can soon vanish and become useless if unrecorded in time. In any case of collision incontrovertible evidence always can be found, which let unfold the course of accident and estimate its parameters. These evidentiary facts are the deformations of the fore of vehicles.

The analysis of the deformations of the fore can provide information about:

- the kind of collision, the angle of collision;

- the force to the fore of the vehicles and their directions;

- the speed of the vehicles before the collision, etc.

The method of estimating the parameters of traffic accident based on the deformations of vehicle surface after collision is presented in this paper.

\section{Cases of car collision with immovable obstacle}

Most common of car collision cases were analyzed in the article: collision with immovable obstacle which deformed only a part of the fore of vehicle (collision with a tree, a bollard, etc.). Such collisions can be central (Fig. 1) and non-central (Fig. 2).

Fig. 1 shows that in the case of central collision the contact of a car with an obstacle happens in the same axis, which goes through the centre of the car. After the contact a car usually moves in the same direction and does not turn around. In the case of non-central collision the axes of a car and an obstacle are not the same and

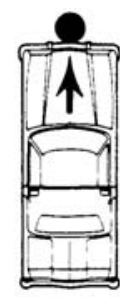

a)

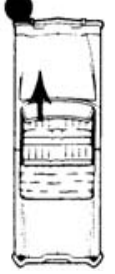

a)

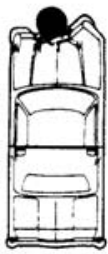

b)

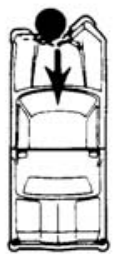

c)
Fig. 1. Central collision with a tree

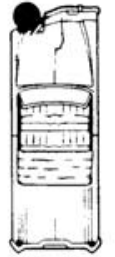

b)

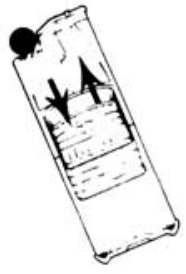

c)
Fig. 2. Non-central collision with a tree

after the contact a car usually turns.

In the case of collision with a flat surface (for example, wall) the deformations of a car spread along all the area of car contact. There are direct collisions (Fig. 3) and angular collisions (Fig. 4).

\section{Method for calculation of car collision parameters}

Vehicles are usually deformed after hit. Analysis of car deformation can define much information about: collision type, collision angle, forces on the transport means, their direction, car speed before hit, etc. 


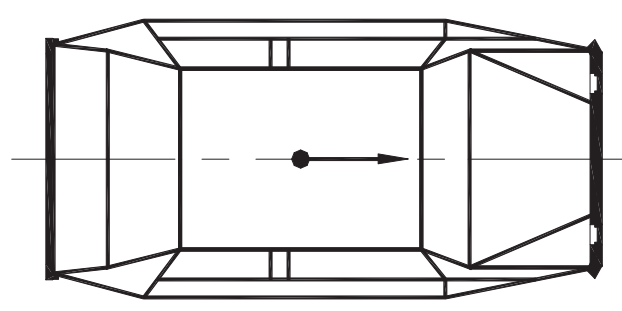

Fig. 3. Direct collision with a wall

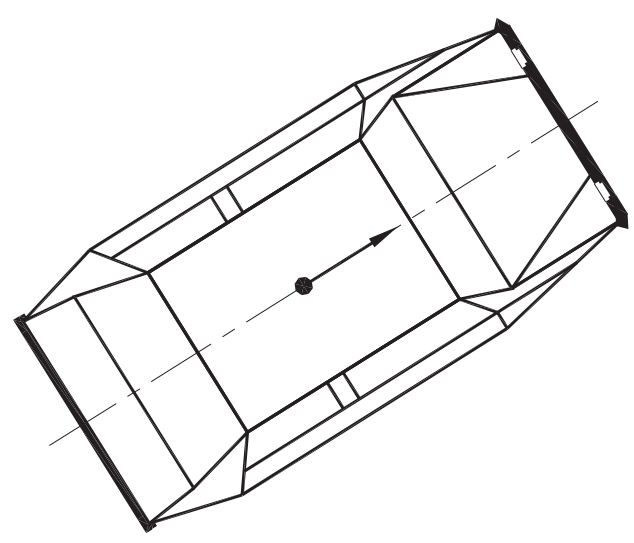

Fig. 4. Angular collision with a wall

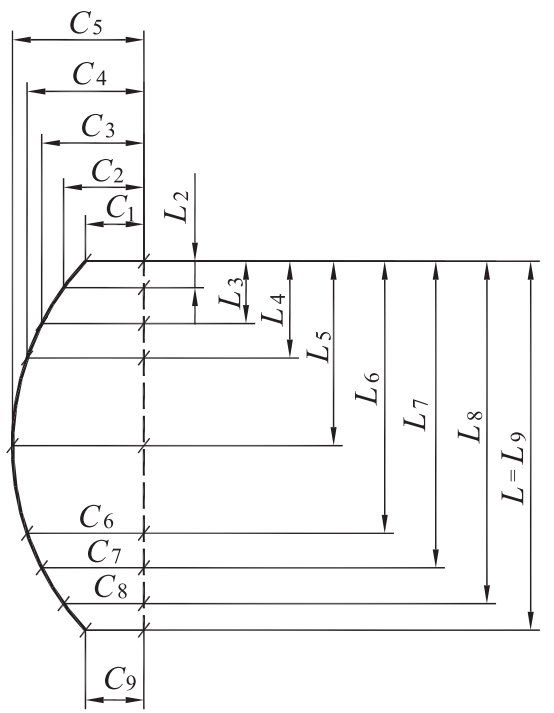

Fig. 5. Scheme of car deformation measurement points after collision with a tree, a bollard, etc.

This article introduces the method of defining the parameters of the car accident based on car deformation after hit. One of the parameters is speed of the car after collision. Firstly, as shown in Fig. 5, car deformation is defined.

After assessing car deformation after hit and its stiffness rate, which is defined experimentally for each model, it is possible to define the energy of car deformation [1]:

$$
\begin{aligned}
& E=\sum_{i=1}^{n-1} k_{i}\left(1+\operatorname{tg}^{2} \theta\right)\left(\frac{B}{6} \cdot \frac{C_{i+1}^{3}-C_{i}^{3}}{C_{i+1}-C_{i}}+\right. \\
& \left.\frac{A}{2}\left(C_{i+1}+C_{i}\right)+(n-1) G\right),
\end{aligned}
$$

where $k_{i}=L / n-1 ; E_{i}$ - the energy used for the car deformation; $C_{i}$ - deformation depth at any point, $\mathrm{mm}$; $i$ - number of points measured; $L_{i}$ - the width of the area deformed, mm; $A_{i}$ - stiffness coefficient, defining the size of contact force according to the area of the surface deformed; $B_{i}$ - stiffness coefficient of the car in trial, defining the size of the contact force according to the deformation depth; $G_{i}$ - stiffness coefficient [2-4].

$$
G_{i}=\frac{A_{i}^{2}}{2 B_{i}},
$$

After having defined the surface of deformation $C_{i}$, and evaluated the energy needed for the car deformation $E_{i}$, it is possible to define the equivalent speed of the car at the moment of hit. This speed can be calculated according to the equation:

$$
V_{e k v}=\sqrt{\frac{2 E}{m}}
$$

where $m$ - the weight of the car.

The energy of two cars used for the car deformations during the collision process spreads through both of them. With the help of linear momentum equations it is possible to design the general equation of energy spreading [5]:

$$
\begin{aligned}
& V_{1}^{2} m_{1}+V_{2}^{2} m_{2}=V_{3}^{2} m_{1}+I_{1} \omega_{1}^{2}+I_{2} \omega_{2}^{2}+ \\
& V_{e k v 1}^{2} m_{1}+V_{4}^{2} m_{2}+V_{e k v 2}^{2} m_{2},
\end{aligned}
$$

where $m_{1}, m_{2}$ - the weight of the first and the second car; $V_{1}, V_{2}$ - the speed of the first and the second car at the moment of hit; $V_{3}, V_{4}$ - the speed of the first and the second car after hit; $I_{1}$ - the momentum of inertia of the first car after hit; $I_{2}$ - the momentum of inertia of the second car after hit; $\omega_{1}$ - the angular acceleration of the first car after hit; $\omega_{2}$ - the angular acceleration of the second car after hit.

Value of $I_{1} \omega_{1}^{2}+I_{2} \omega_{2}^{2}$ equation is often omissible, because it has only inconsiderable influence on the evaluated results.

According to the equation of energy spreading (4), it is possible to evaluate the car speed at the moment of contact.

Calculations performed with the help of software WINCRASH 2.0 [6] based on this model can evaluate the car speed before hit according to the car deformation depth after hit. 


\section{Calculation and investigation of car collision parameters}

\subsection{Central collision with a tree, bollard, etc.}

One of the most important parameters is speed of the vehicle before hit. Such kind of collision always causes car deformation. So it is possible to estimate the speed according to it.

According to the methodology for the estimation of car surface deformation described in the third chapter, the scheme of its estimation is shown in Fig. 5 using computer program 'WINCRASH 2.0'. While designing the central collision with a tree, nine points in the fore of the car were chosen. Such estimation guarantees the accuracy of the counted results. The accident was modelled with some different deformations of the car and different coordination in the place of the accident. Its scheme is shown in Fig. 6.

Car deformation depth after hit with an immovable obstacle depends on car stiffness. Car stiffness is defined by rates, which are set experimentally for each car model.

For investigation of collision with an immovable obstacle, different car models of different classes were selected: 1 - Honda Civic, 2 - WW Golf, 3 - BMW 318, 4 - Volvo S 70, 5 - Audi 100. Their coefficients of stiffness are following: $1-A=65.5 \mathrm{kN} / \mathrm{m}, B=500 \mathrm{kN} / \mathrm{m}^{2}$; $2-A=63.8 \mathrm{kN} / \mathrm{m}, B=400 \mathrm{kN} / \mathrm{m}^{2} ; 3-A=95.2 \mathrm{kN} / \mathrm{m}$, $B=760 \mathrm{kN} / \mathrm{m}^{2} ; 4-A=74.5 \mathrm{kN} / \mathrm{m}, B=480 \mathrm{kN} / \mathrm{m}^{2} ; 5-$ $A=63.9 \mathrm{kN} / \mathrm{m}, B=358 \mathrm{kN} / \mathrm{m}^{2}[1-4]$.

According to the scheme of calculation the dependence of car speed and car deformation has been defined.

As shown in Fig. 7 the car surface deformation depends on car stiffness and the speed $V_{1}$ at the moment of contact. The bigger deformation, the higher speed has been rated. When coefficients of stiffness are the following: $A=65.5 \mathrm{kN} / \mathrm{m}, B=500 \mathrm{kN} / \mathrm{m}^{2}$ (Honda Civic), the highest speed has been observed (Fig. 7 , curve 1), when $-A=63.9 \mathrm{kN} / \mathrm{m}, B=358 \mathrm{kN} / \mathrm{m}^{2}$ (Audi 100), the slowest speed has been observed (Fig. 7,

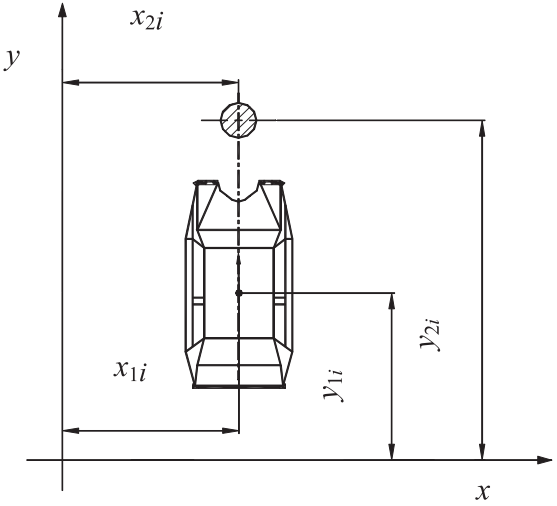

Fig. 6. Scheme of central car collision with a tree, a bollard, etc.

curve 5). In these cases the speed differs twice. In case of the biggest deformation of car surface the coefficients of stiffness are the following: $A=65.5 \mathrm{kN} / \mathrm{m}, B=$ $500 \mathrm{kN} / \mathrm{m}^{2}$, speed $V_{1}$ is $39.7 \mathrm{~km} / \mathrm{h}$ (Fig. 7 , curve 1 ), and when $A=63.9 \mathrm{kN} / \mathrm{m}, B=358 \mathrm{kN} / \mathrm{m}^{2}-V_{1}$ is $21.9 \mathrm{~km} / \mathrm{h}$ (Fig. 7, curve 5). In other cases, when $A=63.8 \mathrm{kN} / \mathrm{m}, B=$ $400 \mathrm{kN} / \mathrm{m}^{2}-V_{1}$ is $32 \mathrm{~km} / \mathrm{h}$ (Fig. 7, curve 2), $A=$ $95.2 \mathrm{kN} / \mathrm{m}, B=760 \mathrm{kN} / \mathrm{m}^{2}-V_{1}=29.9 \mathrm{~km} / \mathrm{h}$ (Fig. 7, curve 3), $A=74.5 \mathrm{kN} / \mathrm{m}, B=480 \mathrm{kN} / \mathrm{m}^{2}, V_{1}=26.9 \mathrm{~km} / \mathrm{h}$.

After having analyzed these results, it is obvious that in estimating the speed of vehicle in case of collision with a tree, it is very important to estimate deformation place of vehicle and to measure linear deformation rates. Also, it is necessary to know coefficients of stiffness of the selected car model.

\subsection{Parameters of calculation in case of non-central collision with a tree}

In contrast to collision with a tree, in case of noncentral collision a vehicle is not only deformed, but usually acquires revolving movement and complicated trajectory after contact.

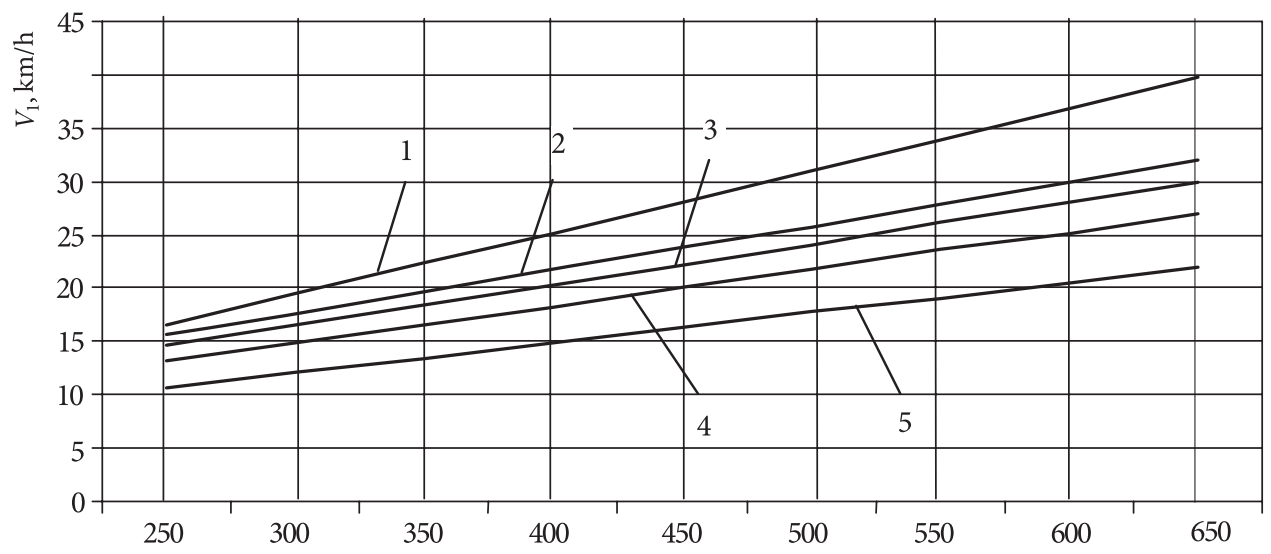

The dimension of basket deformation, $\mathrm{mm}$

Fig. 7. Dependence of car speed before hit and car deformation after hit $C_{i}$ and car stiffness in case of central collision with a tree, when coefficients of stiffness are the following: $1-A=65.5 \mathrm{kN} / \mathrm{m}, B=500 \mathrm{kN} / \mathrm{m}^{2} ; 2-A=63.8 \mathrm{kN} / \mathrm{m}, B=400 \mathrm{kN} / \mathrm{m}^{2}$; $3-A=95.2 \mathrm{kN} / \mathrm{m}, B=760 \mathrm{kN} / \mathrm{m}^{2} ; 4-A=74.5 \mathrm{kN} / \mathrm{m}, B=480 \mathrm{kN} / \mathrm{m}^{2} ; 5-A=63.9 \mathrm{kN} / \mathrm{m}, B=358 \mathrm{kN} / \mathrm{m}^{2}$ 


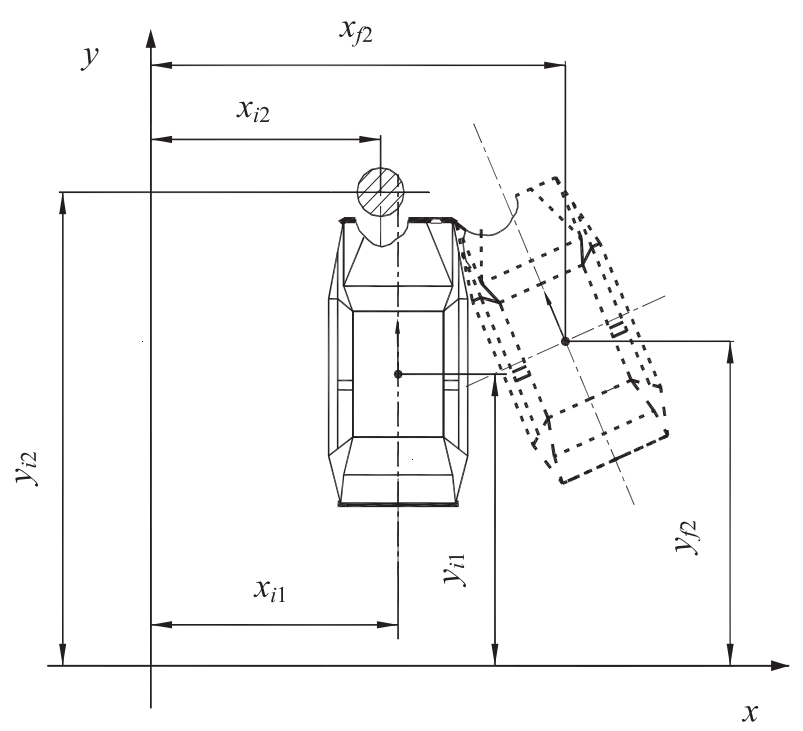

Fig. 8. Scheme of non-central car collision with a tree, a bollard, etc.

The scheme of non-central collision with a tree, a bollard, etc. is shown in Fig. 8. There the coordination of $x_{i 1}$ and $x_{i 2}, y_{i 1}$ and $y_{i 2}$ define the place of hit and coordination of $x_{f 1}$ and $x_{f 2}, y_{f 1}$ and $y_{f 2}$ - the position of the vehicle after the accident.

While modelling a case of non-central collision with a tree, 6 different points of car surface deformation were chosen. The modeling was performed with the help of software WINCRASH 2.0 [6].

Modelling the non-central collision with a round obstacle, the same conditions of the central collision were chosen, i.e. different kinds and classes of vehicles, different stiffness of their basket surface were used for this experiment [2]. The dependence of car surface deformation on car speed at the moment of the hit is shown in Fig. 9.

Modeling a case of non-central collision with a tree, it was noticed that the speed of vehicle at the moment of contact, like in a case of central hitting, impacts on deformation size and car stiffness (Fig. 7). The higher car speed, the bigger deformation size has been rated. The highest speed $V_{1}=63 \mathrm{~km} / \mathrm{h}$ with the biggest deformation $C_{2}=900 \mathrm{~mm}$ has been observed of a car, when coefficients of stiffness are the following: $A=$ $65.5 \mathrm{kN} / \mathrm{m}, B=500 \mathrm{kN} / \mathrm{m}^{2}$ (Honda Civic), the smallest $V_{1}=52 \mathrm{~km} / \mathrm{h}-A=74.5 \mathrm{kN} / \mathrm{m}, B=480 \mathrm{kN} / \mathrm{m}^{2}$ (Volvo $\mathrm{S} 70)$. When deformation size is the smallest $C_{2}=400 \mathrm{~mm}$, the speed is $50 \%$ slower $-V_{1}=33.5 \mathrm{~km} / \mathrm{h}$, when $A=$ $65.5 \mathrm{kN} / \mathrm{m}, \quad B=500 \mathrm{kN} / \mathrm{m}^{2}$ (Honda Civic) and $V_{1}=28.6 \mathrm{~km} / \mathrm{h}$, when $A=74.5 \mathrm{kN} / \mathrm{m}, B=480 \mathrm{kN} / \mathrm{m}^{2}$ (Volvo S70).

\subsection{Analysis of parameters in case of collision with immovable flat obstacle}

In case of oncoming collision with an immovable obstacle (a wall) the car surface deformation has the even distribution. While modelling such a case, the car front deformation was increased from $50 \mathrm{~mm}$ to $450 \mathrm{~mm}$.

The case of collision with a flat surface is shown in Fig. 10.

After having calculated the results, it was noticed that in case of collision with a wall, when the whole car surface is deformed, the number of deformation points

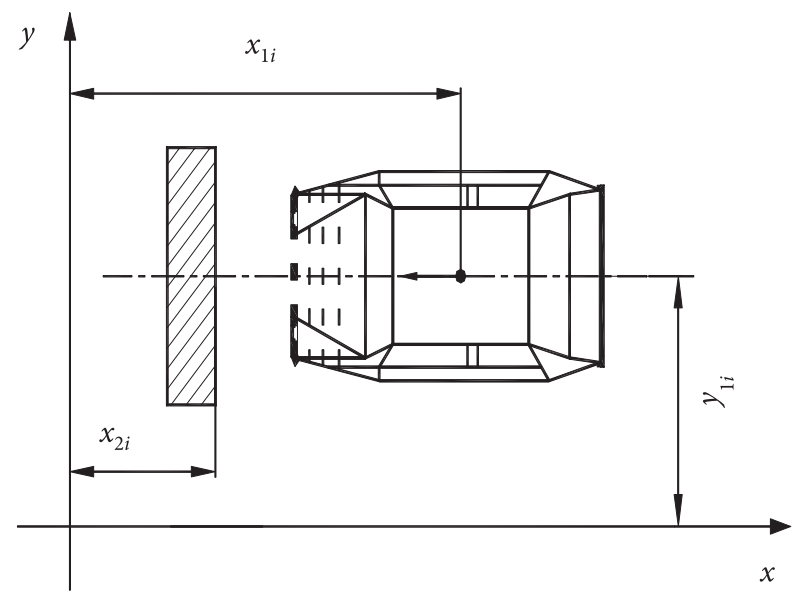

Fig. 10. Scheme of collision with an immovable flat obstacle

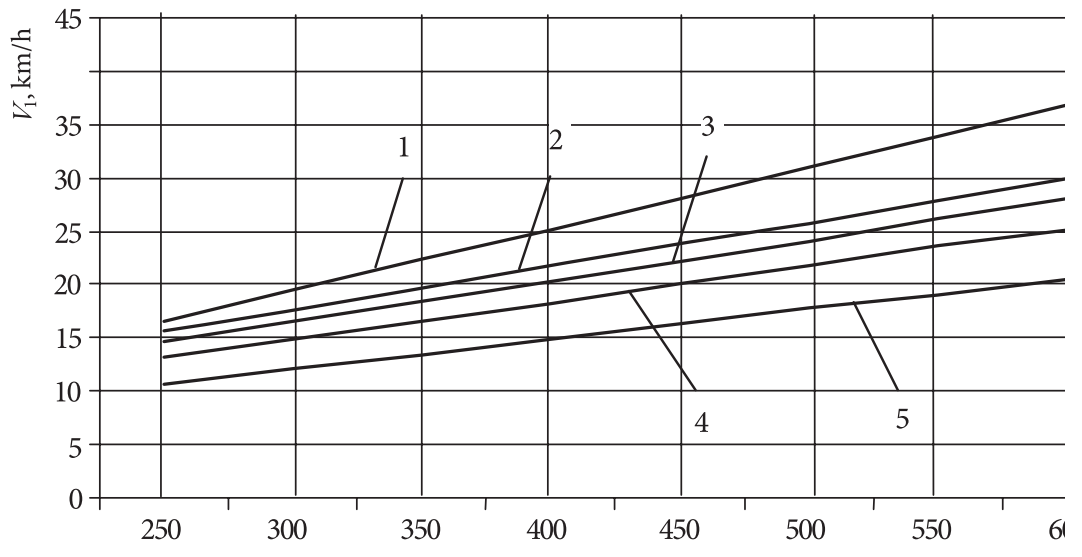

Fig. 9. Dependence of car speed before hit and car deformation after hit $C_{i}$ and car stiffness in case of non-central collision with a tree, when coefficients of stiffness are following: $1-A=65.5 \mathrm{kN} / \mathrm{m}, B=500 \mathrm{kN} / \mathrm{m}^{2} ; 2-A=63.8 \mathrm{kN} / \mathrm{m}, B=400 \mathrm{kN} / \mathrm{m}^{2}$; $3-A=95.2 \mathrm{kN} / \mathrm{m}, B=760 \mathrm{kN} / \mathrm{m}^{2} ; 4-A=74.5 \mathrm{kN} / \mathrm{m}, B=480 \mathrm{kN} / \mathrm{m}^{2} ; 5-A=63.9 \mathrm{kN} / \mathrm{m}, B=358 \mathrm{kN} / \mathrm{m}^{2}$ 


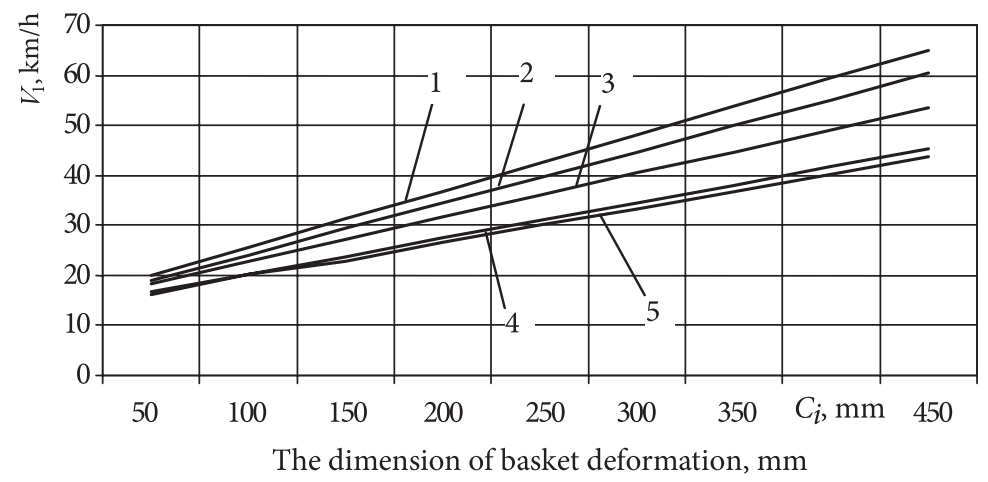

Fig. 11. Dependence of car speed before hit on car deformation after hit $C_{i}$ and car stiffness in case of front collision with a wall, when coefficients of stiffness are the following: $1-A=95.2 \mathrm{kN} / \mathrm{m}, B=760 \mathrm{kN} / \mathrm{m}^{2} ; 2-A=65.5 \mathrm{kN} / \mathrm{m}, B=500 \mathrm{kN} / \mathrm{m}^{2}$; $3-A=63.8 \mathrm{kN} / \mathrm{m}, B=400 \mathrm{kN} / \mathrm{m}^{2} ; 4-A=63.9 \mathrm{kN} / \mathrm{m}, B=358 \mathrm{kN} / \mathrm{m}^{2} ; 5-A=74.5 \mathrm{kN} / \mathrm{m}, B=480 \mathrm{kN} / \mathrm{m}^{2}$

do not have influence on parameters of car accident. Therefore 6 points are enough to assess the deformation of vehicles after contact. Fig. 11 shows dependence of car speed and deformation size and car stiffness in case of collision with a wall.

As shown in Fig. 11, the dependence evaluation lets estimate relation between the car speed $V_{1}$ at the moment of contact and the car deformation size in case of collision with a tree.

The bigger car deformation $C_{i}$, the higher car speed has been observed (Fig. 11, curves $1-5$ ). Car speed $V_{1}$ is not the same for vehicles having different stiffness parameters and the same deformation size $C_{i}$. After having calculated the results, the highest speed at the moment of contact has been observed for vehicles, whose coefficients of stiffness are the following: $A=95.2 \mathrm{kN} / \mathrm{m}, B=$ $760 \mathrm{kN} / \mathrm{m}^{2}$ (BMW 318) (Fig. 11, curve 1), the smallest $-A=74.5 \mathrm{kN} / \mathrm{m}, B=480 \mathrm{kN} / \mathrm{m}^{2}$ (Volvo S 70) (Fig. 8, curve 5).

\section{Conclusions}

1. The model has been created, which lets evaluate the speed of vehicles at the moment of hit as well as estimate the deformations of vehicle surface $C_{i}$ after hit. This model is especially indispensable to estimate the speed of vehicle at the moment of collision with an immovable obstacle.

2. Computer modelling of collision with an immovable round obstacle (tree, bollard, etc.) and with a flat obstacle (wall, fence, etc.) has been done. Collisions were modelled with different car models and different stiffness of their basket surface: Honda Civic, 2 - WW Golf, 3 - BMW 318, 4 - Volvo S 70, 5 - Audi 100, when the coefficient of stiffness is: $1-\mathrm{A}=95.2 \mathrm{kN} / \mathrm{m}, \mathrm{B}=760 \mathrm{kN} / \mathrm{m}^{2} ; 2-\mathrm{A}=$ $65.5 \mathrm{kN} / \mathrm{m}, \mathrm{B}=500 \mathrm{kN} / \mathrm{m}^{2} ; 3-\mathrm{A}=63.8 \mathrm{kN} / \mathrm{m}, \mathrm{B}=$ $400 \mathrm{kN} / \mathrm{m}^{2} ; 4-\mathrm{A}=63.9 \mathrm{kN} / \mathrm{m}, \mathrm{B}=358 \mathrm{kN} / \mathrm{m}^{2} ; 5-$ $\mathrm{A}=74.5 \mathrm{kN} / \mathrm{m}, \mathrm{B}=480 \mathrm{kN} / \mathrm{m}^{2}$. The model and the dependence results show the relation between the speed of vehicle at the moment of hit and the deformation of its basket surface after hit.

3. After having done the modelling of collisions it can be claimed that the size and weight of vehicle do not always have influence on the parameters of collision. It was estimated that the stiffness of basket surface has the biggest influence on them (it was defined as stiffness coefficients A and B).

4. The bigger deformation of car surface, the higher car speed was defined at the moment of the accident. While comparing the deformations it was estimated that the highest speed was reached by Honda Civic, and the lowest by Audi 100 with the same deformation level. The speed differed twice. When the deformations $C_{i}$ are small (50-100 mm), the speed differed up to 1,2 times with different car basket stiffness.

5. After having done the research it can be concluded that in estimating the car speed at the moment of collision with an immovable obstacle it is very important to estimate the deformation place of car surface and measure its linear size.

\section{References}

1. NEPTUNE, JAMES, A. Comparison of crush stiffness characteristics from partial overlap and full-overlap frontal crash tests. SAE Paper 1999.

2. NEPTUNE, JAMES, A.; FLYNN, J. E. A method for determining accident specific crush stiffness coefficients. SAE paper No. 940913, 1994.

3. Stiffness Coefficients for Vehicle Model Years 1960-1994, Neptune Engineering Clovis, CA.

4. NHTSA Crash test Reports No. 114, 435 - 609

5. ILARIONOV, V. A. Examination of car accidents (Исследования автодорожных происшествий). Moscow: MADI, 1989. 240 p. (in Russian)

6. AITools WinCRASH User's Guide. Trantech Corporation, USA, 1998. $233 \mathrm{p}$. 